\title{
EDUCAÇÃO AMBIENTAL POR MEIO DO REAPROVEITAMENTO DO LIXO PELOS ALUNOS DO IFPA
}

\author{
Kayury Serrão da Silva ${ }^{1}$ \\ Edna dos Santos Lobato ${ }^{2}$ \\ Paula Sabrina Bronze Campos ${ }^{3}$ \\ Vinicius de Moura Oliveira ${ }^{4}$
}

Resumo: Este trabalho surgiu a partir da preocupação com os inúmeros impactos causados pela destinação inadequada do lixo na sociedade, ocasionado pela falta de consciência das pessoas. Diante disso, se propôs desenvolver consciência ambiental aliada à sua prática em uma turma do curso de meio ambiente do Instituto Federal de Educação, Ciências e Tecnologias do Pará - IFPA campus Abaetetuba. Os objetivos principais foram incentivar a mudança de hábitos diante do uso de recursos naturais e mostrar a importância da reutilização dos lixos descartados no meio ambiente. Constatou-se que a educação ambiental na comunidade escolar funciona como instrumento eficaz de interação entre sociedade e natureza que contribui para o bem do meio ambiente.

Palavras-chave: Meio Ambiente; Educação Ambiental; Conscientização.

Abstract: This work arose from the concern with the innumerable impacts caused by the inadequate disposal of garbage in society, caused by people's lack of awareness. In view of this, it was proposed to develop environmental awareness allied to its practice in a class of the environment course of the Federal Institute of Education, Sciences and Technologies of Pará - IFPA campus Abaetetuba. The main objectives were to encourage the change of habits in the face of the use of natural resources and to show the importance of the reuse of discards discarded in the environment. It was verified that environmental education in the school community functions as an effective instrument of interaction between society and nature that contributes to the good of the environment.

Keywords: Environmental; Environmental Education; Awareness.

\footnotetext{
${ }^{1}$ Instituto Federal de Educação, Ciências e Tecnologias do Pará. E-mail: kayury.silva@hotmail.com. 2 Instituto Federal de Educação, Ciências e Tecnologias do Pará. E-mail: ednalobato04@gmail.com ${ }^{3}$ Instituto Federal de Educação, Ciências e Tecnologias do Pará. E-mail: paulabronze96@hotmail.com

${ }^{4}$ Instituto Federal de Educação, Ciências e Tecnologias do Pará. E-mail: vmoura@ufam.edu.br
} 


\section{Introdução}

A Educação Ambiental desempenha o importante papel de despertar na sociedade o compromisso com a preservação do ambiente, trabalhando a mudança de comportamento, conceitos e valores em relação ao meio em que vivemos. Para Loureiro $(2009,25-26)$ a Educação Ambiental é considerada:

uma prática que dialoga com a questão ambiental. E no senso comum, essa educação visa a mudança de valores, atitudes e comportamento para o estabelecimento de uma outra relação entre o ser humano e a natureza.

Sabe-se que, um dos grandes desafios para os governantes é saber como garantir qualidade de vida para as pessoas, já que muitas cidades não estão prontas para receber a grande quantidade de lixo destinada a lixões a céu aberto, e que consequentemente causam não só doenças para a população, mas também, um enorme impacto ambiental (DREW, 1998).

Em virtude disso, foram criadas várias medidas para conscientizar a população sobre o descarte apropriado do material consumido, tendo como exemplos a reciclagem e reutilização, as quais geram oportunidades de mobilização e participação comunitárias, desenvolvendo nos cidadãos à consciência ambiental e uma atitude de responsabilidade em relação ao lixo por eles gerado. A realização dessas atividades, quer sejam industriais ou artesanais, bem como as centrais de triagem ou usinas de compostagem, além de serem unidades de tratamento do lixo, podem funcionar como grandes laboratórios de Ciências, oportunizando a aprendizagem de conceitos científicos, habilidades e valores relacionados ao bom manuseio do lixo urbano (ALENCAR, 2005).

Essas medidas contribuem para a diminuição da exploração dos recursos naturais, redução da poluição do solo, da água e do ar, prolongamento da vida útil dos aterros sanitários, diminuição dos custos da produção, com o aproveitamento de recicláveis pelas indústrias, redução do desperdício, diminuição dos gastos com a limpeza urbana, promovem a oportunidade de fortalecer organizações comunitárias e geram emprego e renda pela comercialização dos recicláveis.

Este cenário motivou a elaboração deste trabalho, uma vez que ensinar Educação Ambiental nas escolas é uma forma de despertar nos alunos o interesse em compreender um dos maiores problemas que estão a sua volta, os impactos causados pelo homem na natureza, visto que a escola é um espaço ideal para intensificar a sensibilização a esse assunto, pois desperta no aluno os princípios de respeito e cidadania com o meio ambiente.

Diante disso, o intuito do projeto é conscientizar os alunos do primeiro ano do curso integrado de Meio Ambiente do Instituto Federal de Ciências e Tecnologias do Pará - IFPA, da importância de preservar o meio ambiente, 
mostrando aos alunos que só ter compreensão dos impactos causados na natureza não basta, é preciso ter atitudes que demonstrem cuidados perante as questões ambientais, uma vez que a Educação Ambiental não deve ser tratada como algo distante do cotidiano dos alunos, mas como parte de suas vidas.

\section{Breve histórico da Educação Ambiental}

Apesar de práticas referentes a Educação Ambiental ocorrerem há algum tempo, foi em 1972, que ocorreu o primeiro evento para definir os rumos da Educação Ambiental, este evento ficou conhecido como Conferência de Estocolmo, na mesma foram elaborados dois documentos: a "Declaração Sobre Meio Ambiente Humano" e o "Plano de Ação Mundial" (CADERNOS SECAD, 2007).

Já em 1975, ocorreu a segunda conferencia a qual foi realizada em Belgrado - atual lugoslávia, onde foi criado o Programa Internacional de Educação Ambiental (PIEA), nele são definidos os princípios e orientações para o futuro - a Educação Ambiental deve ser continuada, multidisciplinar, integrada às diferenças regionais e voltada para os interesses nacionais-, este encontro resultou em um documento denominado "Carta de Belgrado". Em 1977 foi realizada a Conferência Intergovernamental de Educação Ambiental em Tbilisi, sendo esta a primeira conferência a nível internacional para tratar assuntos referentes a Educação Ambiental, organizada pela UNESCO (ZANARDI, 2010).

No Brasil, a Constituição Federal de 1988 introduziu pela primeira vez um capítulo para tratar somente assuntos referentes ao Meio Ambiente, considerando o mesmo como um bem comum do povo e essencial a qualidade de vida. Em 1992 foi realizado no Rio de Janeiro a Conferência das Nações Unidas sobre o meio ambiente e desenvolvimento, a qual ficou conhecida como Rio-92, no qual foi criado o Tratado de Educação Ambiental para Sociedades Sustentáveis e Responsabilidade Global, nesta conferência também foi aprovada pelo governo a Agenda 21, sendo esta um plano de ação para ser adotado global, nacional e localmente. Foram designados o Programa Nacional de Educação Ambiental (PRONEA) e o IBAMA como responsáveis pelo cumprimento destas metas (MEDEIROS et al., 2011).

Em 1997 foram elaborados pelo Ministério da Educação os Parâmetros Curriculares Nacionais - PCNs, os quais determinaram que o meio ambiente deveria ser trabalhado nas escolas com tema transversal no currículo básico do ensino fundamental (MEDEIROS et al., 2011). Já em abril de 1999 foi criada a Lei 9.795, a qual fala sobre a Educação Ambiental e institui a Política Nacional de Educação Ambiental, a partir disso a Educação Ambiental passa a ter várias definições. 


\section{Importância de se trabalhar a Educação Ambiental na escola}

A Educação Ambiental é uma disciplina bem estabelecida que enfatiza a relação dos homens com o ambiente natural, as formas de conservá-lo, preservá-lo e de administrar seus recursos adequadamente (UNESCO 2005, p. 44), neste sentido, a escola é uma parte integrante e importante na sociedade, então é importante oferecer meios para que seus alunos participem de manifestações, criando a sua consciência crítica e comprometida com o meio ambiente (TRINDADE, 2011).

Os educadores têm um papel fundamental na inserção da Educação Ambiental, o docente precisa ter como horizonte a transformação de hábitos, mobilizando os discentes para formação da consciência ambiental (TRINDADE, 2011). Para o ensino, o educador deve utilizar diversas estratégias para que a prática de Educação Ambiental estimule os alunos, e que estes preservem o meio ambiente, além disso, deve promover a integração entre a escola e a comunidade, objetivando a proteção ambiental em harmonia com o desenvolvimento sustentável (KNORST, 2011).

Quando a conscientização de Educação Ambiental está inserida nas escolas, proporcionando a organização coletiva, amplia o conhecimento científico e mobiliza a participação ativa dos alunos na busca de soluções para reverter os problemas ambientais. De acordo com os Parâmetros Curriculares Nacionais:

o trabalho de Educação Ambiental deve ser desenvolvido a fim de ajudar os alunos a construírem uma consciência global das questões relativas ao meio para que possam assumir posições afinadas com valores referentes sua proteção e melhoria. Para isso é importante que possam atribuir significado aquilo que aprendem sobre a questão ambiental. E esse significado é resultado da ligação que o aluno estabelece entre o que apreende e a sua realidade cotidiana [...] (BRASIL, 2001, p.47-48).

Diante deste cenário, a Educação Ambiental é um processo pelo qual o educando começa a obter conhecimentos acerca das questões ambientais, onde ele passa a ter uma nova visão sobre o meio ambiente e se torna um agente transformador em relação à conservação ambiental.

\section{Metodologia}

O projeto foi desenvolvido pelos alunos do curso de Licenciatura em Ciências Biológicas do Instituto Federal de Educação, Ciências e Tecnologias do Pará - IFPA, campus Abaetetuba, durante a disciplina de Educação Ambiental. Para o desenvolvimento do projeto, foi escolhida uma turma de primeiro ano do curso integrado de Meio Ambiente do IFPA onde foram utilizados os dois últimos horários da disciplina de Educação Ambiental ministrada pela Prof. Me. Dirlene Silva.

revista brasileira educação ambiental 
Em um primeiro momento foi realizado o levantamento bibliográfico, efetuado por meio de livros, monografias, artigos e sites. Esta pesquisa proporcionou a ampliação do entendimento sobre o tema dando embasamento para a prática em sala.

O contato inicial com a turma aconteceu no dia 09 de outubro de 2018, esse momento teve como finalidade apresentar a equipe e o projeto à turma. No dia 16 de outubro de 2018 de volta à sala de aula, deu-se continuidade ao projeto aplicando um questionário com cinco perguntas referentes às questões ambientais, os alunos tiveram em torno de 15 minutos para o preenchimento, o mesmo teve como objetivo analisar os conhecimentos que os alunos já possuíam antes da aplicação do projeto.

Nesta mesma manhã, logo após a aplicação do questionário organizou-se a turma para iniciar uma roda de conversa na qual os alunos tiveram a oportunidade de expor suas opiniões e dúvidas sobre o tema, nesse momento os alunos demonstraram bastante interesse, pois contribuíram mencionando ações do seu dia-a-dia favoráveis ao meio ambiente.

Em seguida foram trabalhados com os alunos, em forma de palestra, tópicos como a definição de lixo, suas classificações, seus impactos causados ao meio ambiente e por último a importância dos 5 R's (Repensar, Reduzir, Recusar, Reutilizar e Reciclar), reforçando com os alunos como as práticas desse último tópico contribui com a redução da produção de lixo no meio ambiente. Nesse momento as dúvidas apresentadas na roda de conversa foram esclarecidas, principalmente sobre os 5 R's, pois muitos não tinham esse conhecimento. Para esse momento, utilizou-se recursos audiovisuais, tais como: apresentação em Power Point e utilização de imagens e vídeos relacionados a abordagem do tema. Este momento teve como intenção conscientizar os alunos sobre as consequências causadas pela desordenada produção de lixo e seus impactos ocasionados na natureza, demonstrando para eles atitudes que podem ser tomadas para preservar o meio ambiente.

Em seguida, para colocar em prática o que foi abordado em sala de aula os alunos foram organizados em cinco equipes, onde cada equipe ficou responsável por trabalhar a reutilização em um dos 5 materiais sugeridos, foram eles: Plástico, Papel, Metal, Material de informática e Madeira (Palitos de fosforo, talas de picolé e churrasco), a divisão dos temas ocorreu em forma de sorteio entre os representantes das equipes, cada equipe ficou encarregada por produzir no mínimo dois materiais reutilizáveis, além de elaborar um texto explicando a importância da conscientização ambiental. O mesmo texto e materiais produzidos pelas equipes foram utilizados pela professora da disciplina como forma de avaliação para a composição da nota bimestral dos alunos. Para essa produção foi estipulado para a turma um período de duas semanas de tempo.

No dia 30 de outubro de 2018 houve retorno à sala de aula para avaliar a apresentação das produções das equipes. Foi demonstrado empenho pelos alunos na elaboração dos materiais, durante suas apresentações explicaram o 
local da coleta, como foram construídos, o tempo que leva para esses materiais sofrerem decomposição na natureza e a importância de reutilizar e reciclar. Muitos dos materiais elaborados pelas equipes do plástico e metal foram ilustrações natalinas, todos esses materiais foram doados para o IFPA com a intenção de contribuir com a decoração da instituição no mês de dezembro.

Para finalizar esse encontro os alunos foram orientados a escolherem um representante da equipe para publicar suas produções junto ao texto elaborado na sua conta do Facebook marcando a conta oficial do IFPA no site, para que os aplicadores do projeto tivessem controle do número de curtidas em cada trabalho. Para essa etapa os alunos tiveram um período de três dias.

O encerramento do projeto teve como culminância no dia 01 de novembro de 2018 no Hall do Instituto Federal de Educação, Ciências e Tecnologias do Pará - IFPA campus Abaetetuba a exposição dos textos e os materiais confeccionados pelos alunos. Esse momento se deu durante o intervalo, no período da manhã, foi entregue também nesse momento a premiação do trabalho mais curtido nas redes sociais. Esta ação teve como intuito levar os conhecimentos adquiridos pelos alunos durante a aplicação do projeto para a comunidade local através das exposições e das redes sociais.

\section{Resultados e discussão}

Foram aplicados questionários com a turma para avaliar o conhecimento e o interesse que os alunos têm pela temática de reutilização de materiais que são considerados lixo. Ao analisar as respostas do questionário, observou-se que os alunos tinham uma ideia básica do que são impactos ambientais. Em $77 \%$ das respostas relacionaram os impactos ambientais à atividade humana (Figura 1).

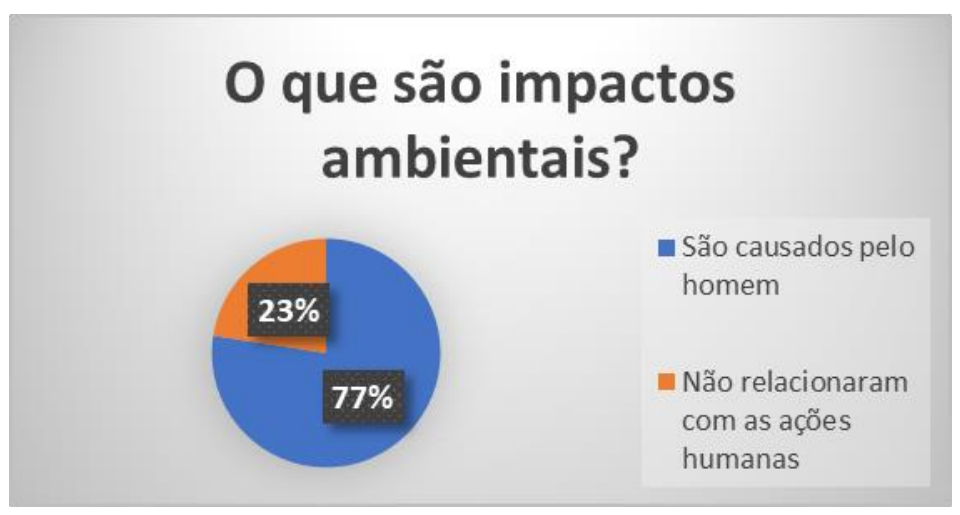

Figura 1: Resultados da primeira pergunta do questionário.

Na segunda pergunta 26 alunos afirmaram que não conhecem os " 5 R's", apenas 5 alunos afirmaram que conhecem e comentaram sobre o assunto, como mostra a Figura 2. 


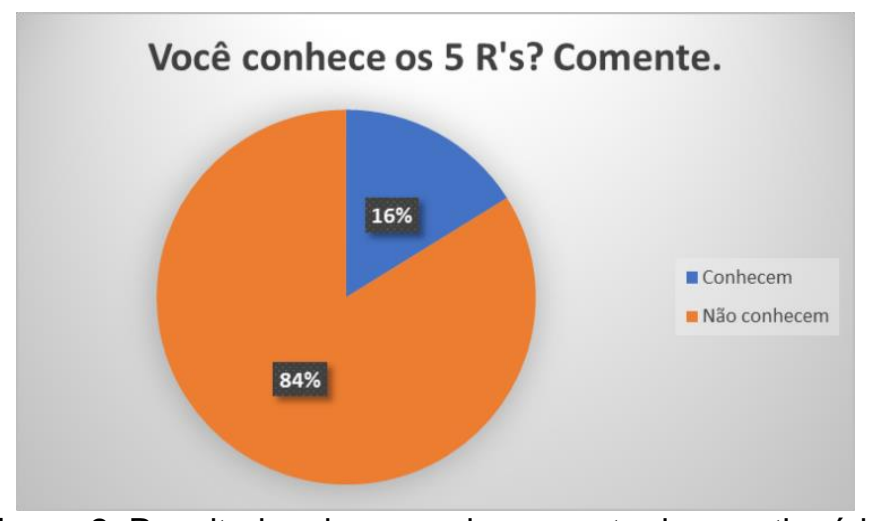

Figura 2: Resultados da segunda pergunta do questionário.

$\mathrm{Na}$ terceira pergunta 25 alunos afirmaram que têm alguma atitude para melhorar as condições do meio ambiente, e 6 responderam que não.

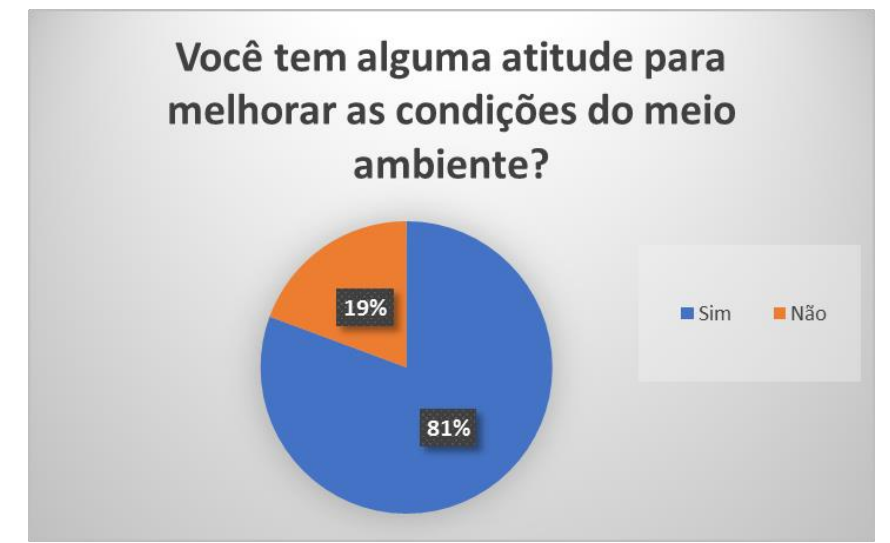

Figura 3: Resultado da terceira pergunta do questionário.

$\mathrm{Na}$ quarta pergunta, 20 dos entrevistados demonstraram muito interesse por assuntos relacionados ao meio ambiente, 6 tem interesse razoável, 5 acham pouco interessante e 0 dos entrevistados tem nenhum interesse.

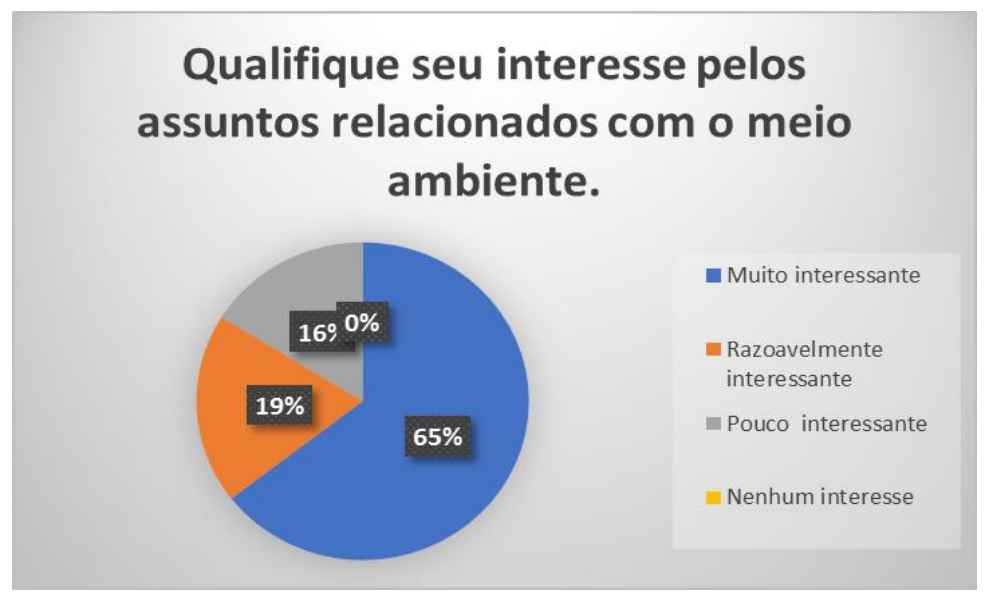

Figura 4: Resultado da quarta pergunta do questionário.

Revbea, São Paulo, V. 15, № 3: 400-409, 2020. 
Quanto à quinta pergunta - 28 dos entrevistados responderam que a solução dos problemas ambientais está relacionada a pequenas ações de todos, no seu dia-a-dia, 3 responderam que depende das decisões do governo e das grandes empresas e 0 não sabe responder.

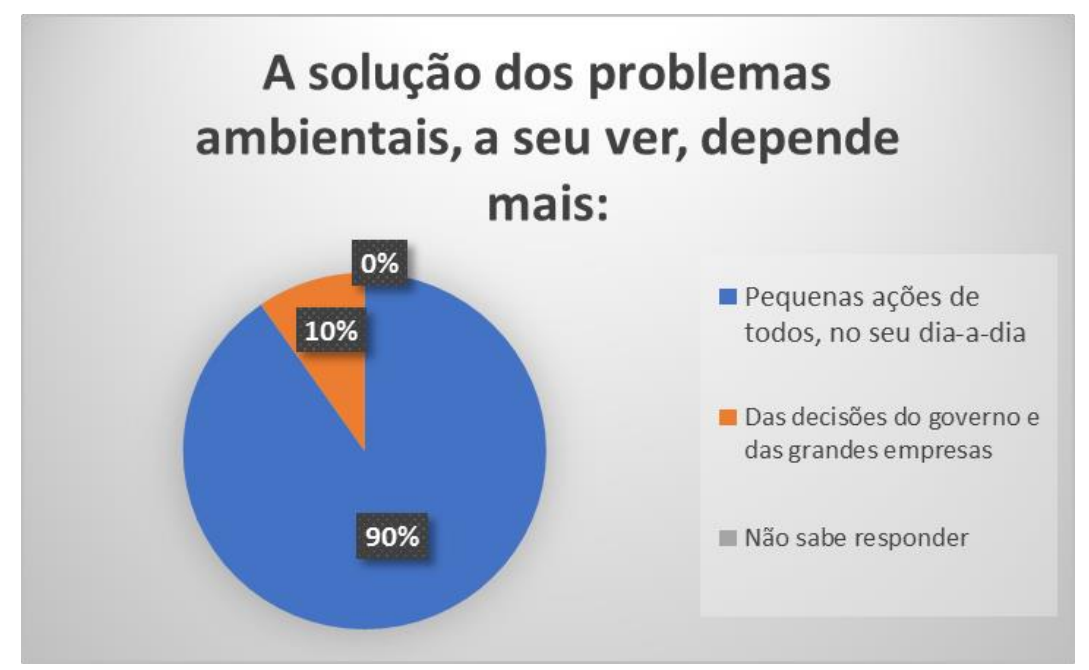

Figura 5: Resultado da quinta pergunta do questionário.

A partir da análise dos questionários conclui-se que, antes da palestra os alunos possuíam um conhecimento básico quanto aos impactos ambientais, mas insuficiente no que se refere às atitudes que podemos tomar, como os 5 R's em que $84 \%$ dos alunos não conheciam. Quanto ao interesse por assuntos relacionados ao meio ambiente, apenas $65 \%$ dos alunos apresentaram muito interesse antes da palestra, o que não era um dado muito satisfatório, sabendo da importância do tema, e que estão em um curso de Meio Ambiente.

Além do questionário, os foram orientados alunos a produzir alguns objetos a partir de materiais reutilizáveis, para que assim pudessem praticar atitudes sustentáveis, e não ficar apenas na teoria. E que criassem textos falando da importância do lixo. E a partir desses textos foi possível observar que a maioria dos alunos, estavam realmente preocupados em buscar mais conhecimento e melhorarem suas atitudes em relação ao desperdício do lixo.

Foi interessante perceber que eles buscaram conhecimentos do que acontece em sua cidade, trazendo o que está na realidade deles, e isso foi possível pelo estímulo que lhes foi dado na escola. Então, as escolas são muito importantes para a sociedade, pois são autoras de muitas transformações que ocorrem em nosso meio. Segundo Leff (2001, p.257) a Educação Ambiental traz consigo uma nova pedagogia que surge da necessidade de orientar a educação dentro do contexto social e na realidade ecológica e cultural onde se situam os sujeitos e atores do processo educativo.

Estudar as questões ambientais nas aulas é contribuir para a formação de cidadãos conscientes, responsáveis e críticos, e isso se torna um grande desafio para os professores. Freire (1987), diz que ninguém pode ser uma 
pessoa neutra perante o mundo; ou adere uma mudança social ou se permanece na qual está. Feita a opção, irá determinar seu papel na sociedade. Então os professores devem, além de ser incentivadores dos alunos, ter atitudes sustentáveis, ter uma posição crítica em relação a Educação Ambiental.

Juntamente, como resultado do presente trabalho, foi realizado a "EduComunicação", onde os alunos divulgaram as suas produções textuais e materiais, na rede social Facebook e fizeram uma pequena exposição no hall de entrada do Instituto, em que as pessoas poderiam participar expondo suas opiniões a respeito da reutilização do lixo.

Para Freire (1987), os homens são seres que não podem ser fora da comunicação, pois são comunicação. Obstaculizar a comunicação é transformá-los em quase "coisa" e isto é tarefa e objetivo dos opressores, não dos revolucionários. A comunicação é o que conecta as pessoas e permite o aprendizado. A comunicação é o meio pelo qual a educação acontece.

\section{Considerações finais}

Ao longo do trabalho percebeu-se que diante dos inúmeros impactos causados ao meio ambiente pelo descarte inadequado de lixo produzido pela população, a Educação Ambiental surge como uma importante contribuição para amenizar esse quadro e assim incentivar o consumo sem exageros. Diante disso muitas medidas podem ser tomadas, uma delas é a conscientização através de palestras sobre os 5 R's apresentados neste trabalho, pois favorece o consumo consciente dos produtos naturais e a utilizar de forma inteligente o lixo produzido, dessa forma o lixo passa de um problema para solução.

Os resultados da pesquisa através do questionário foram considerados expressivos, pois os alunos demonstraram que possuem conhecimentos sobre os impactos ambientais e expressaram interesse em melhorar as condições do ambiente, entretanto um aspecto preocupante foi a alta porcentagem no número de alunos que não tem conhecimento sobre os 5 R's, uma vez que esse é um fator muito importante para mudanças de comportamento, além da turma estar em um curso de Meio Ambiente, todos os assuntos dessa natureza devem ser indispensáveis em suas formações.

Algo que trouxe muita satisfação foi a reutilização de materiais apresentados pelos alunos, pois permitiu acreditar que com ela podemos ajudar a reduzir o problema do acúmulo de lixo em nossa sociedade, porém se torna fundamental que mais pessoas contribuam com essas práticas, visto que, por menor que sejam, favorecem o bem do meio ambiente.

Levando isso em consideração, entende-se que a escola desenvolve um papel fundamental ao estimular essa conscientização, pois amplia os conhecimentos dos alunos na busca de soluções dos impactos causados na natureza.

Revbea, São Paulo, V. 15, № 3: 400-409, 2020. 


\section{Referências}

ALENCAR, M.M.M. Reciclagem de lixo numa escola pública do município de salvador. Revista Virtual, v. 1, n. 2, p. 96-113, 2005.

BRASIL. Ministério da Educação. Secretaria da Educação Fundamental, Parâmetros Curriculares Nacionais: meio ambiente. sade. 3. ed Braslia-DF, 2001.

CADERNOS SECAD. Secretaria de Educação Continuada, Alfabetização e Diversidade. Ministério da Educação. Secretaria de Educação Continuada, Alfabetização e Diversidade (Secad/MEC) Educação Ambiental: aprendizes de sustentabilidade. Brasília - DF, março de 2007, p.20.

COLAVITTI, F. O que fazer com o lixo?. Revista Galileu, n. 143, p. 39-50, 2003.

DREW, D. Processos Interativos homem-ambiente. 4. ed. Rio de Janeiro: Bertrand Brasil. 1998.

FREIRE, P. Pedagogia do Oprimido. 17. ed. Rio de Janeiro: Paz e Terra, 1987.

JACOBI, P. Educação Ambiental, Cidadania e Sustentabilidade. Cadernos de Pesquisa, n. 118, p.189-205, março/ 2003.

KNORST, P.A.R. Educação Ambiental: um desafio para as unidades escolares. Unoesc \& Ciência-ACHS, v. 1, n. 2, p. 131-138, 2011.

LEFF, E. Saber ambiental: sustentabilidade, racionalidade, complexidade, poder. Petrópolis/RJ: Ed. Vozes, 2001.

LOUREIRO, C. F.; LAYRARGUES, P.P.; CASTRO, R.S. (orgs.). Repensar a Educação Ambiental: um olhar critico. São Paulo: Cortez, 2009.

MEDEIROS, A. B. et al. A Importância da Educação Ambiental na escola nas séries iniciais. Revista Faculdade Montes Belos, v. 4, n. 1, set. 2011

TRINDADE, N. A. D. Consciência ambiental: coleta seletiva e reciclagem no ambiente escolar. Enciclopédia Biosfera, v. 7, n. 12, p. 1-15, 2011.

UNESCO. Década da Educação das Nações Unidas para um Desenvolvimento Sustentável, 2005-2014: documento final do esquema internacional de implementação, Brasília, Brasil, 2005.

ZANARDI, B. N. Concepções de Educação Ambiental de graduandas em Pedagogia. Trabalho de Conclusão de Curso apresentado à Universidade Presbiteriana Mackenzie. São Paulo, 2010. 